\title{
Use of the poc® decision support system for the analysis of economic decision- making in a natural products company
}

\section{Dalilla de Medeiros Praxedes ${ }^{1}$, Maycon Wendell Lima dos Santos ${ }^{2}$, Raimundo Alves de Carvalho Junior ${ }^{3}$, Rubens Mendonça de Souza Neto ${ }^{4}$, Saulo de Morais Dantas ${ }^{5}$}

\author{
1,2,3,4,5 Universidade Federal Rural do Semi-Árido (UFERSA). \\ Email: dalyllapraxedess2@hotmail.com, mayconsantos-@hotmail.com,junior.r.a.c.j@hotmail.com, rubens-vale@hotmail.com, \\ saulo_dantas_92@hotmail.com
}

Received: March 27th, 2017

Accepted: April $12^{\text {th }}, 2017$

Published: June $30^{\text {th }}, 2017$

Copyright $@ 2016$ by authors and Institute of Technology Galileo of Amazon (ITEGAM). This work is licensed under the Creative Commons Attribution International License (CC BY 4.0).

http://creativecommons.org/lic enses/by/4.0/ (c) (1) (2) Opean Aecen

\section{ABS TRACT:}

The natural products sector, which concentrates a large part of its production in small and micro-enterprises, with a rustic or even artisanal production system, is also susceptible to market weather and consequently, it is of fundamental importance the knowledge and use of costing methods And tools that assist in decision making. This case study aims to demonstrate the operation of the POC® system in four specific products of a natural products company located in the city of Mossoró / RN. In the definition of the products, the ones that had the greatest demands were chosen, they are: Lambedor, Sesame Fubá, Corn Fubá and Sunflower Oil. The product that presented the highest real contribution margin was sunflower oil with $73.25 \%$. The ABC curve of material costs made it possible to identify that Hortelã represented 27,628 of the total cost of materials for the period. The construction of the $\mathrm{ABC}$ product billing curve made it possible to identify that Lambedor represented $39.303 \%$ of the total turnover for the period. It is convenient that this work, as well as the tool used, can be used continuously by the company in all its portfolio, in an unrestricted way.

Keywords: $P O C \circledR$, Decision, ABC, Natural Products.

\section{Utilização Do Sistema De Apoio À Decisão Poc® Para A Análise Da Tomada De Decisões Econômicas Em Uma Empresa De Produtos Naturais}

\begin{abstract}
RESUMO
$\mathrm{O}$ setor de produtos naturais, que concentra boa parte de sua produção nas pequenas e microempresas, com um sistema produtivo rústico ou até mesmo artesanal, também está suscetível às intempéries do mercado e consequentemente, é de fundamental importância o conhecimento e utilização de métodos de custeio e ferramentas que auxiliem na tomada de decisão. Este estudo de caso tem como finalidade demonstrar a operacionalização do sistema POC® em quatro produtos específicos de uma empresa de produtos naturais localizada na cidade de Mossoró/RN. Na definição dos produtos, foram escolhidos os que apresentavam maiores demandas, são eles: Lambedor, Fubá de gergelim, Fubá de milho e Óleo de girassol. O produto que apresentou maior margem real de contribuição foi óleo de girassol com 73,25\%. A curva ABC de custos de materiais possibilitou identificar que a Hortelã representou 27,628 do custo total com materiais do período. A construção da curva $\mathrm{ABC}$ de faturamento dos produtos possibilitou identificar que o Lambedor representou $39,303 \%$ do faturamento total do período. É conveniente que este trabalho, assim como a ferramenta utilizada, possa ser utilizado continuamente pela empresa em todo o seu portfólio, de maneira irrestrita.
\end{abstract}

Palavras-Chaves: POC®, Decisão, ABC, Produtos Naturais.

\section{INTRODUÇÃO}

Toda decisão econômica tomada dentro de uma empresa contribui de forma direta ou indireta para a falha ou o sucesso da mesma, sendo que cada escolha determina um resultado final diferente. Porém, no cenário atual, se torna cada vez mais crítico esse processo, pois nos deparamos com desajustes de mercado, desequilíbrios nas taxas de juros, intervenções frequentes nas regras da economia, dentre outros desajustes, que exige do decisor uma capacidade mais minuciosa das unidades decisórias. O setor de produtos naturais, que concentra boa parte de sua produção nas pequenas $\mathrm{e}$ 
microempresas, com um sistema produtivo rústico ou até mesmo artesanal, também está suscetível às intempéries do mercado e consequentemente, é de fundamental importância o conhecimento e utilização de métodos de custeio e ferramentas que auxiliem na tomada de decisão. Conforme apontam [1][2][3], é um importante alicerce para a gestão das organizações, a utilização de forma adequada dos dados financeiros da organização. Dentre as ferramentas e sistemas de apoio a decisão, destacamos o POC® Preços, Orçamentos e Custos Industriais, que possibilita a realização de um estudo do sistema produtivo e de seus custos, fazendo uma análise da situação estudada com simulações para situações específicas, em um momento atual ou futuro, possibilitando ao gestor uma visão holística de todo o processo produtivo numa ótica econômico-financeira [4].
A empresa estudada pelo presente artigo possui uma dificuldade em mensurar e visualizar seu sistema financeiro, apresentando uma carência na forma de mensurar seus custos, preços e lucros, utilizando-se para isso apenas conhecimentos básicos e informais. Dessa forma, esse estudo foi desenvolvido com o objetivo de analisar a tomada de decisão financeira referente aos produtos principais de uma empresa de produtos naturais do Rio Grande do Norte, utilizando assim o sistema de apoio à decisão POC®.

A contabilidade de custos funciona como um processador de informações. Ela informa ao administrador quais os resultados que necessitam de uma atenção maior e auxilia na solução de vários problemas. Na figura 1 vemos a atividade de contabilidade de custos como um centro de processador de informações:

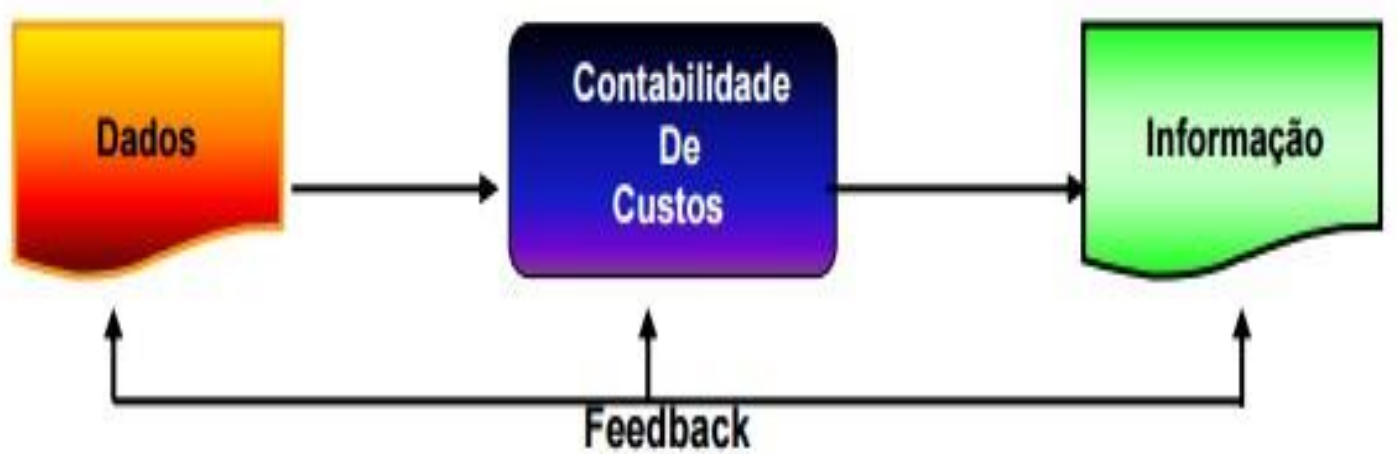

Figura 1: Contabilidade de custos.

Fonte: [6].

Segundo [1], a contabilidade gerencial é o processo de identificar, mensurar, relatar e analisar as informações sobre os eventos econômicos da organização. Dessa forma, a contabilidade gerencial pode ser entendida como um processo de produção de informações financeiras e operacionais, tanto para funcionários quanto para gerentes, sendo orientado pelas necessidades de informações internas. Para contabilidade gerencial, os custos dos produtos e dos processos são importantes e justamente para is so é utilizado o sistema de apoio à decisão POC®.

\section{II.2. O SISTEMA DE APOIO À DECISÃO POC®.}

O POC® foi desenvolvido, principalmente, com o objetivo de apoiar a gestão econômico-financeira de operações, principalmente às de manufatura, nos seguintes aspectos [4]:

- Quantificação de custos de produtos, subconjuntos e atividades;

- Cálculo da margem de contribuição unitária, por tipo de produto e total da empresa;

- Cálculo do ponto de equilíbrio da operação; • Simulação das relações custo-volume-lucro (CVL);

- Formação de preço de venda de produtos;

- Orçamentos de pedidos;

- Análise econômica do mix de produtos;

- Análise econômica de substituição e alteração de recursos produtivos;

- Análise econômica de terceirizações de produtos, subconjuntos e atividades.

\section{REFERENCIAL TEÓRICO.}

\section{II.1. CONTABILIDADE DE CUSTOS E CONTABILIDADE GERENCIAL.}

Para [5], "a contabilidade de custos refere-se hoje às atividades de coleta e fornecimento de informações para as necessidades de tomada de decisão de todos os títulos, desde as relacionadas com operações repetitivas até as de natureza estratégica, não repetitivas, e, ainda, ajuda na formulação das principais das políticas das organizações" [2], completa essa ideia afirmando que "a contabilidade de custos é uma atividade que se assemelha a um centro de processador de informações, que recebe (ou obtém) dados, acumula-os de forma organizada, analisa-os e interpreta-os, produzindo informações de custos para os diversos níveis gerenciais".

Para utilizar o sistema POC®, o método de custeio usado deve ser o direto, também chamado de custeio variável ou custeio marginal, que atribui para cada custo uma classificação específica, sendo custo fixo ou custo variável. Nesse método extrai-se a margem de contribuição, os custos variáveis são alocados aos produtos, e os custos fixos são considerados despesas, indo para o resultado.

O modelo econômico do POC® resume-se assim: 
Praxedes et al., ITEGAM-JETIA. Vol. 03, № 10, pp.149-163. Junho, 2017.

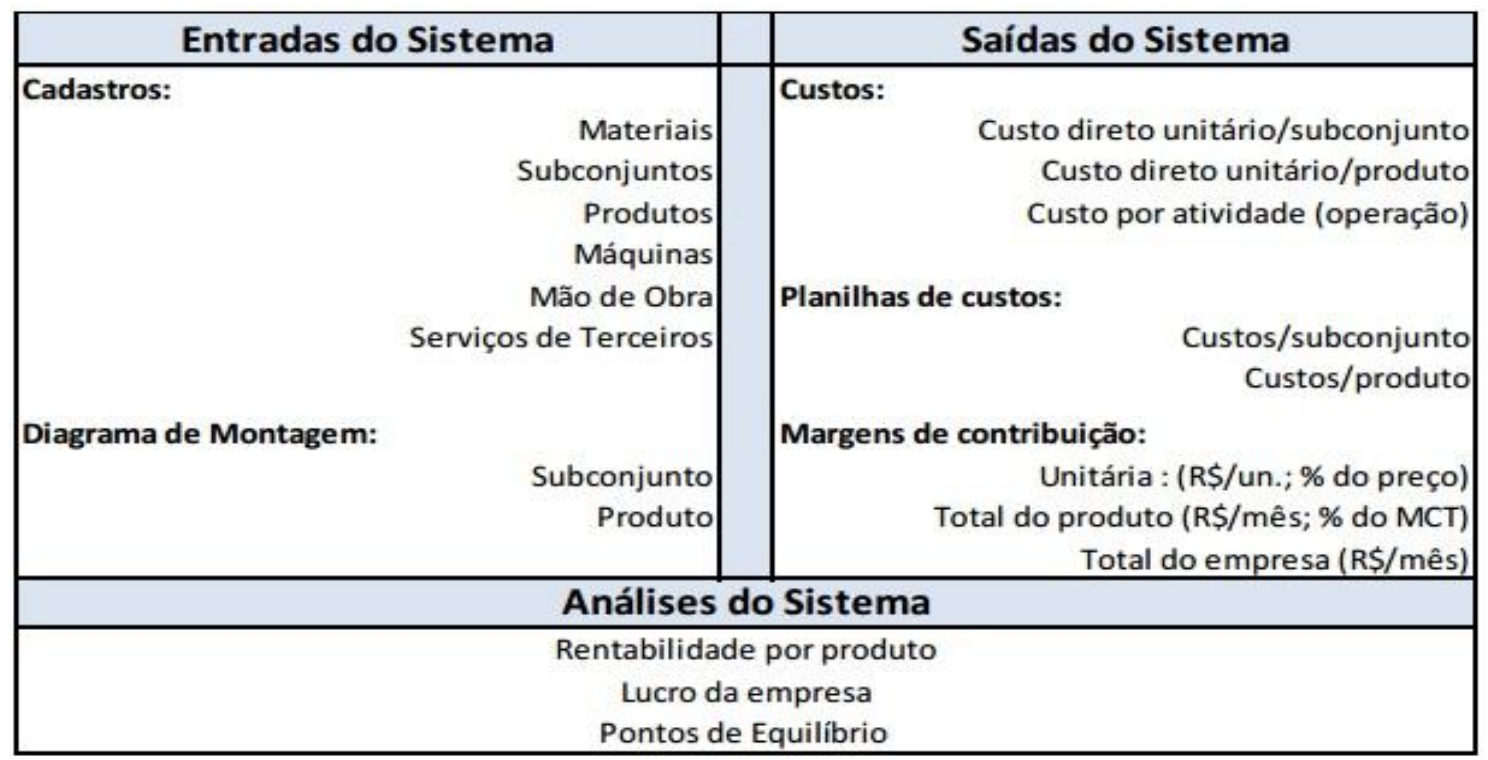

Figura 2: Entradas e Saídas do POC®.

Fonte: Adaptado do [4].

Essa ferramenta se mostra bastante eficiente quanto um sistema de modelagem econômico-financeira que auxilia a gestão da produção, pois o POC® possibilita um planejamento dos preços, planejamento dos materiais e de capacidade, o calculo do ponto de equilíbrio, dentre outras funcionalidades. Dessa forma se os resultados não forem satisfatórios, mudam-se preços e quantidades, simulando uma nova operação, até se obter o esperado. O sistema POC ${ }^{\circledR}$ constrói a formulação do preço nas seguintes situações: formação do preço à vista, a partir do custo direto, dos impostos e da margem de contribuição; formação do preço à vista com vários prazos de pagamento de impostos e taxas; formação do preço com base no critério margem de contribuição sob o preço; e, ainda, ao se fornecer preço, o sistema apresenta a margem de contribuição resultante [4].

\section{II.3 MARGEM DE CONTRIBUIÇÃO E PONTO DE EQUILÍBRIO.}

De acordo com [7] define a margem de contribuição como o "reflexo" de quanto tal produto contribui para o faturamento da empresa. A margem de contribuição é resultante do cálculo: $\mathrm{MCU}=\mathrm{PV}-(\mathrm{CV}+\mathrm{DV})$, onde MCU é a margem de contribuição unitária do produto, PV é o Preço de Venda líquido unitário, CV é o Custo Variável unitário e DV é a Despesa Variável unitária. Sendo assim, a margem de contribuição é o todo da receita retirando os custos variáveis. O ponto de equilíbrio é um indicador de segurança do negocio, pois mostra o quanto é necessário vender para que as receitas se igualem aos custos. Ele indica em que momento, a partir das projeções de vendas do empreendedor, a empresa estará igualando suas receitas a seus custos. Com isso, é eliminada a possibilidade de prejuízo em sua operação [8]. Segundo [4], a imagem representada abaixo ilustra graficamente o ponto de equilíbrio. Ela explicita as curvas de custo fixo (constante em relação ao volume de vendas), custo variável, custo total, receita e lucro, obtido pela diferença entre a receita total e os custos totais.

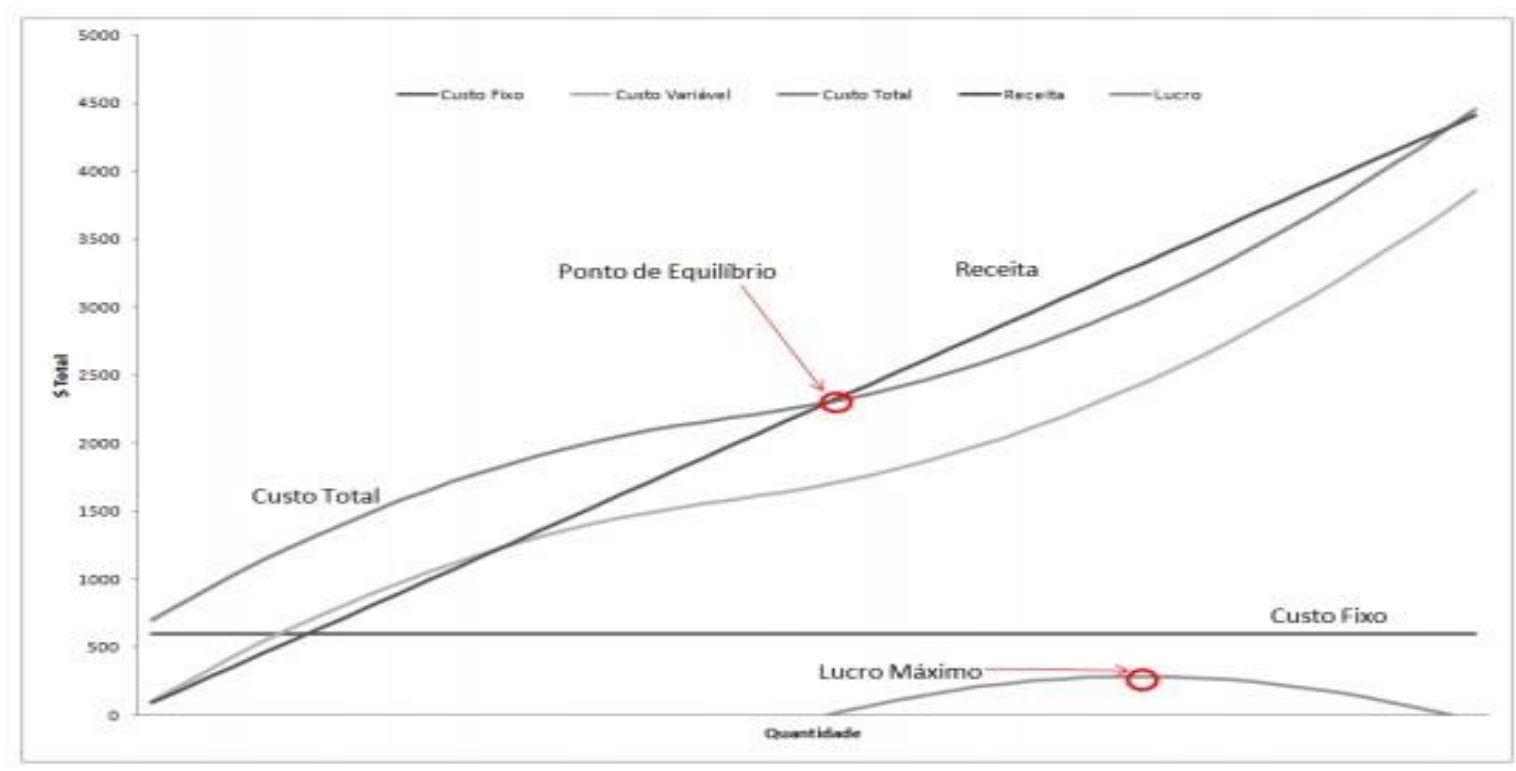

Figura 3: Gráfico do ponto de equilíbrio.

Fonte: Adaptado de [4]. 


\section{II.4 MRP I E CRP.}

O MRP I, material requirement planning e o CRP, capacity requirement planning, são ferramentas utilizadas para $\mathrm{o}$ planejamento e programação de um processo produtivo, sendo que o MRP I trata do planejamento da necessidade de materiais e o CRP trata do planejamento da capacidade de produção da empresa.

Para [9] dizem que o MRP permite o cálculo de materiais quanto à quantidade e necessidade: O MRP I permite que as empresas calculem quanto material de determinado tipo é necessário e em que momento. Para fazer isso, utiliza os pedidos em carteira, as sim como previsões de pedidos que a empresa acha que irá receber. O MRP verifica, então, todos os ingredientes necessários para completar esses pedidos, garantindo que sejam providenciados a tempo. De acordo [10] define CRP como a Metodologia que "[...] especifica os tempos de cada operação de fabricação. Somando-se os tempos consumidos nas etapas de um produto final, temos o total de mão de obra direta de fabricação, assim é possível agendar o inicio e o termino de cada produto final $[\ldots] ”$.

\section{II.4.1 CURVA ABC}

Segundo [10], a curva ABC trata-se de classificação estatística de materiais, baseada no princípio de Pareto, em que se considera a importância dos materiais, baseada nas quantidades utilizadas e no seu valor. Também pode ser utilizada para classificar clientes em relação aos seus volumes de compras ou em relação à lucratividade proporcionada; classificação de produtos da empresa pela lucratividade proporcionada, etc. Para [12] dividem a curva ABC em três grupos:

- Itens A: componentes ou produtos cujos estoques apresentam elevados valores relativos, merecendo uma maior atenção.

- Itens B: componentes ou produtos que também apresentam elevada aplicação de recursos, mas não são tão representativos quantitativamente quanto os itens $\mathrm{A}$.
- Itens C: estoques numerosos em itens, mas representam pouco em valores e merecem menos destaque.

Uma classificação $\mathrm{ABC}$ de itens de estoque tida como típica apresenta uma configuração na qual $20 \%$ dos itens são considerados A e que estes respondem por $65 \%$ do valor de demanda ou consumo anual. Os itens B representam $30 \%$ do total de número de itens e $25 \%$ do valor de demanda ou consumo anual. Tem-se ainda que os restantes $50 \%$ dos itens e $10 \%$ do valor de consumo anual serão considerados de clas se C. [13].

\section{METODOLOGIA APLICADA}

Como destaca [14] "pode-se definir pesquisa como o procedimento racional e sistemático que tem como objetivo proporcionar respostas aos problemas que são propostos". A pesquisa se faz necessário quando as informações são insuficientes para responder ao problema ou estão de forma desorganizadas. Segundo [15], "a pesquisa, portanto, é um procedimento formal, com método de pensamento reflexivo, que requer um tratamento cientifico e se constitui no caminho para conhecer a realidade ou para descobrir verdades parciais".

A metodologia aplicada nesse trabalho se enquadra na forma de: pesquisa exploratória, na etapa da pesquisa bibliográfica; e de natureza descritiva, pois, por meio do levantamento de dados busca-se traçar as características de um determinado processo produtivo, desta forma o presente trabalho é caracterizado como sendo um estudo de caso. Segundo [16], "a principal diferença entre o estudo de caso e outras possibilidades de pesquisa é o foco de atenção do pesquisador que busca a compreensão de um particular caso, em sua idiossincras ia, em sua complexidade". Este estudo de caso tem como finalidade demonstrar a operacionalização do sistema POC® em quatro produtos específicos de uma empresa de produtos naturais localizada na cidade de Mossoró/RN. Na definição dos produtos, foram escolhidos os que apresentavam maiores demandas, são eles: Lambedor, Fubá de gergelim, Fubá de milho e Óleo de girassol. Este estudo está mostrado no fluxograma da figura 4.

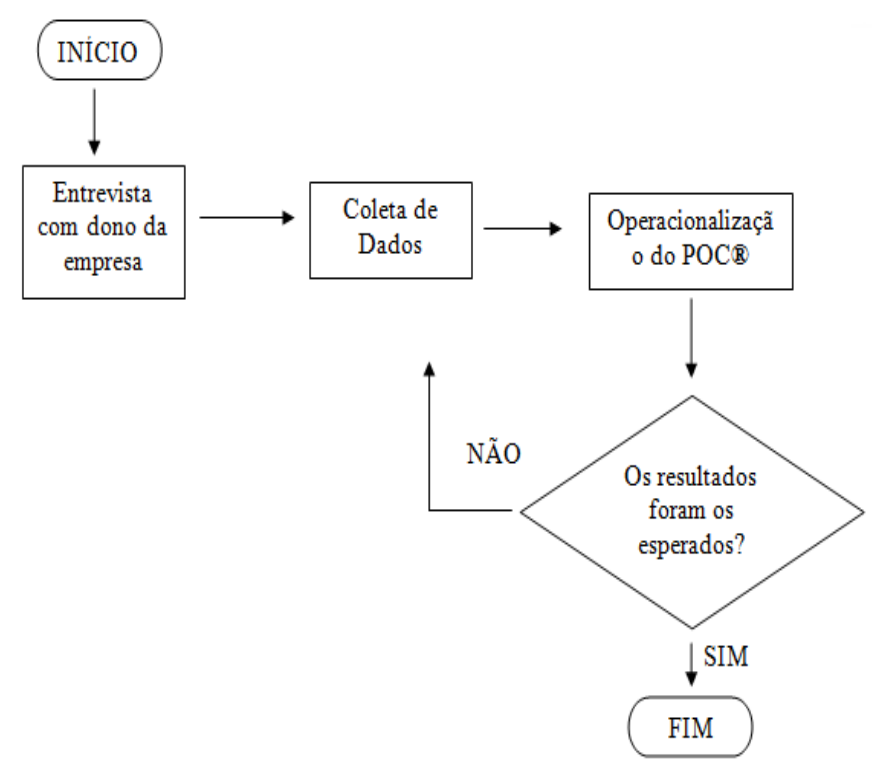

Figura 4: Fluxograma do Processo do Sistema POC®

Fonte: Autores, (2016). 
Primeiramente foi feito uma entrevista com o dono da empresa para ter o conhecimento dos produtos naturais que requeriam maiores demandas e entender como funciona cada processo. Em seguida, foi feito a coleta dos dados necessários para se realizar o estudo. Assim, em cima dos dados coletados, houve a utilização do sistema POC® para a análise da modelagem econômica.

\section{IV.RESULTADOS E DISCUSSÕES}

O presente estudo tem como objetivo a aplicação do sistema POC® em uma empresa do ramo de produtos naturais da

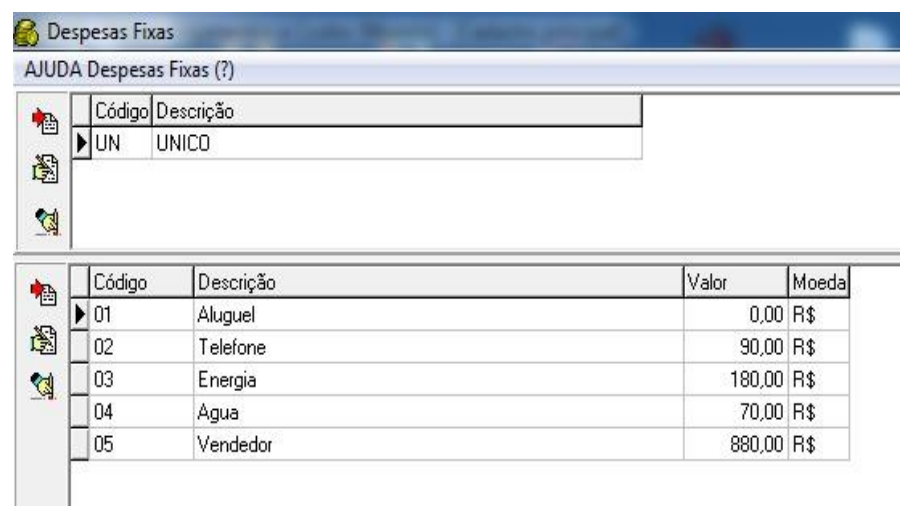

Figura 5: Cadastro das despesas fixas no sistema POC®. Fonte: Autores, (2016).

Em seguida, foram realizados os cadastros dos produtos finais no sistema. Para isto, foram especificadas algumas informações para cada produto, relativas à quantidade mensal, dimensão (Kg = quilograma, utilizado para a fuba de milho e de cidade de Mossoró, no Rio Grande do Norte. A empresa produz diversos tipos de produtos naturais, tais como lambedor (tradicional, hortelã, abacaxi e alho), fuba de gergelim, fuba de milho, óleo de girassol, óleo de coco extra virgem, farinha de linhaça marrom e dourada, entre outros, fornecendo para Mossoró e região. Os produtos analisados foram: fuba de milho, fuba de gergelim, lambedor (tradicional) e óleo de girassol.

Inicialmente foram cadastradas as despesas fixas da empresa estudada, conforme se pode observar na Figura 5. Quanto ao imposto, Figura 6, foi utilizada a incidência direta apenas do ICMS.

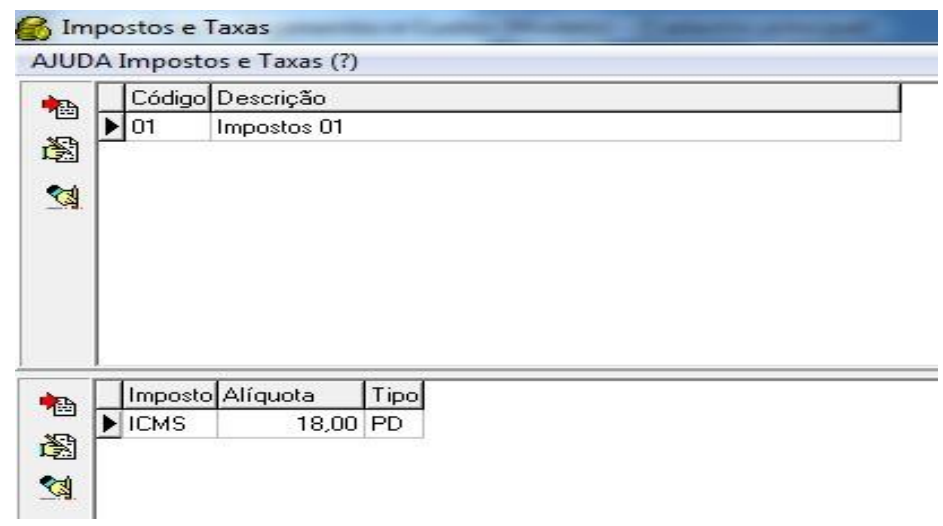

Figura 6: Cadastro dos impostos ou taxas.

Fonte: Autores, (2016).

gergelim. $\mathrm{L}=$ litro, utilizados para o lambedor e o óleo de girassol), valor (referente ao preço de venda liquido), moeda (R\$), e aos impostos que incidem sobre a venda (ICMS), de acordo com a Figura 7:

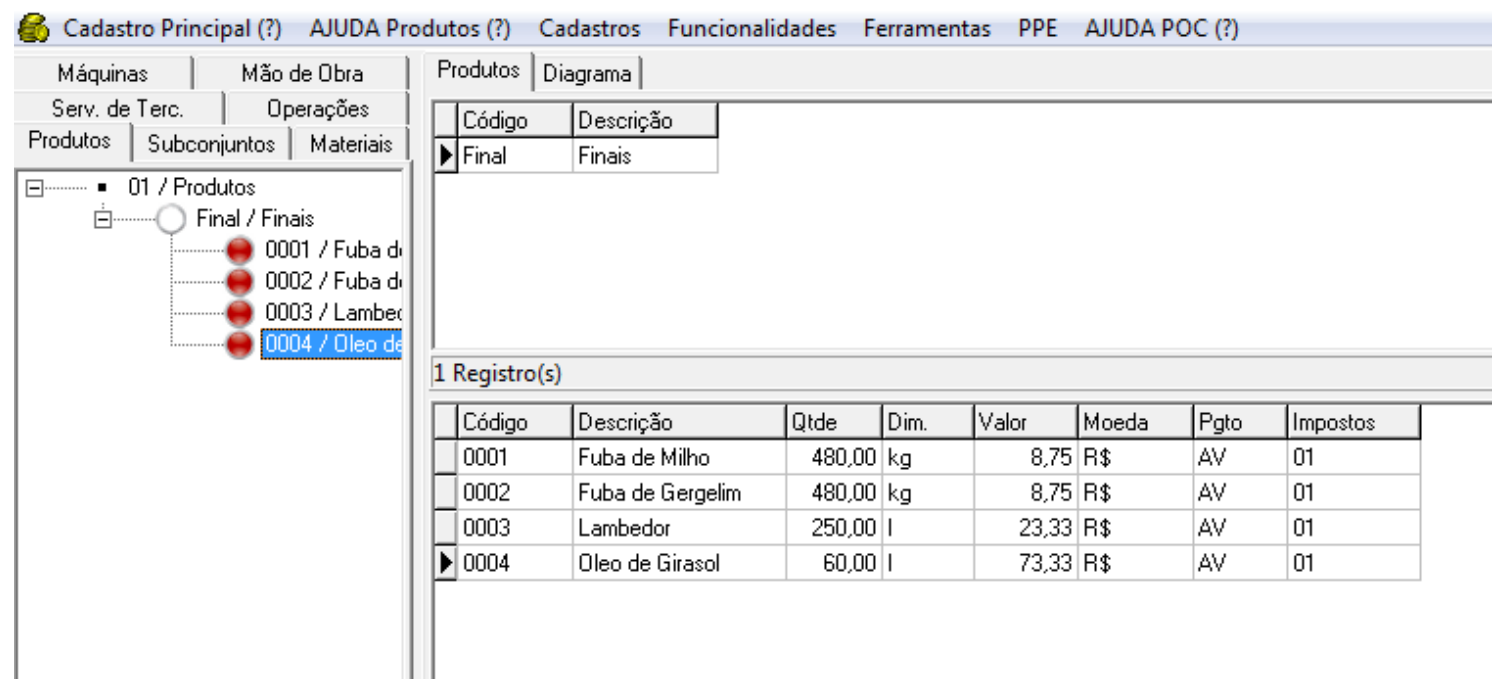

Figura 7: Cadastro dos produtos finais no sistema.

Fonte: Autores, (2016).

A próxima etapa foi o cadastro dos materiais utilizados diretamente no processo produtivo, para a fabricação da fuba de milho e de gergelim, foram identificados: milho, açúcar, gergelim, farinha e rapadura, como mostra a Figura 7. No processo de fabricação do lambedor, são utilizados os produtos: limão, malva e hortelã, podendo ser observada na Figura 8. Para o óleo de girassol, o processo é mais simples, conta apenas comas sementes de girassol, como mostra a Figura 9. 


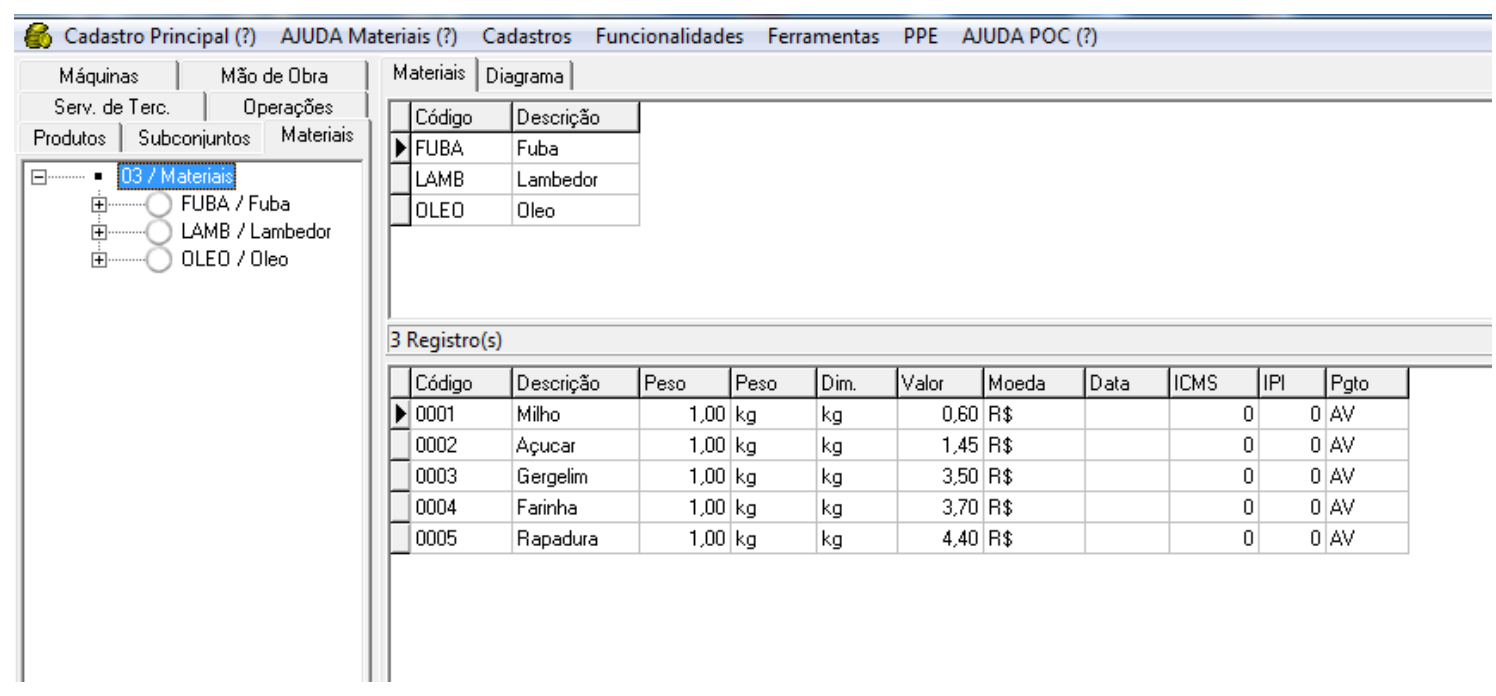

Figura 8: Cadastro dos materiais para fabricação da fuba de milho e de gergelim.

Fonte: Autores, (2016).

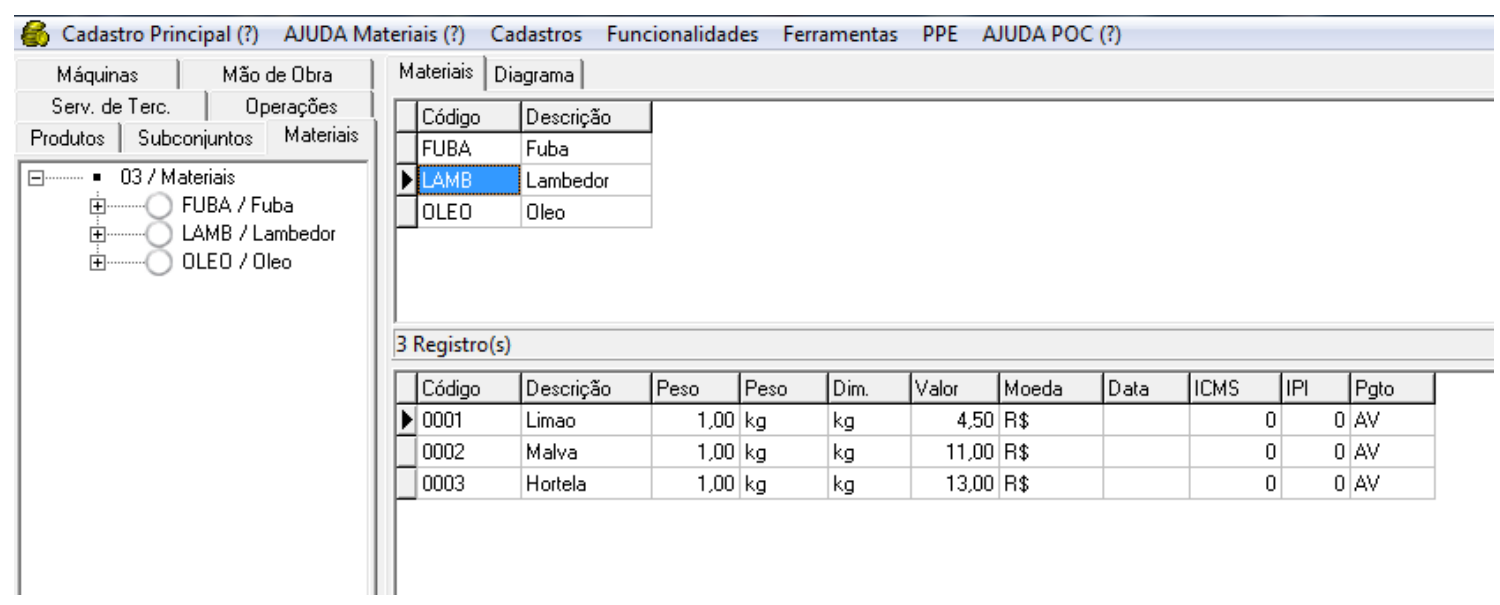

Figura 9: Cadastro dos materiais utilizados na fabricação do lambedor.

Fonte: Autores, (2016).

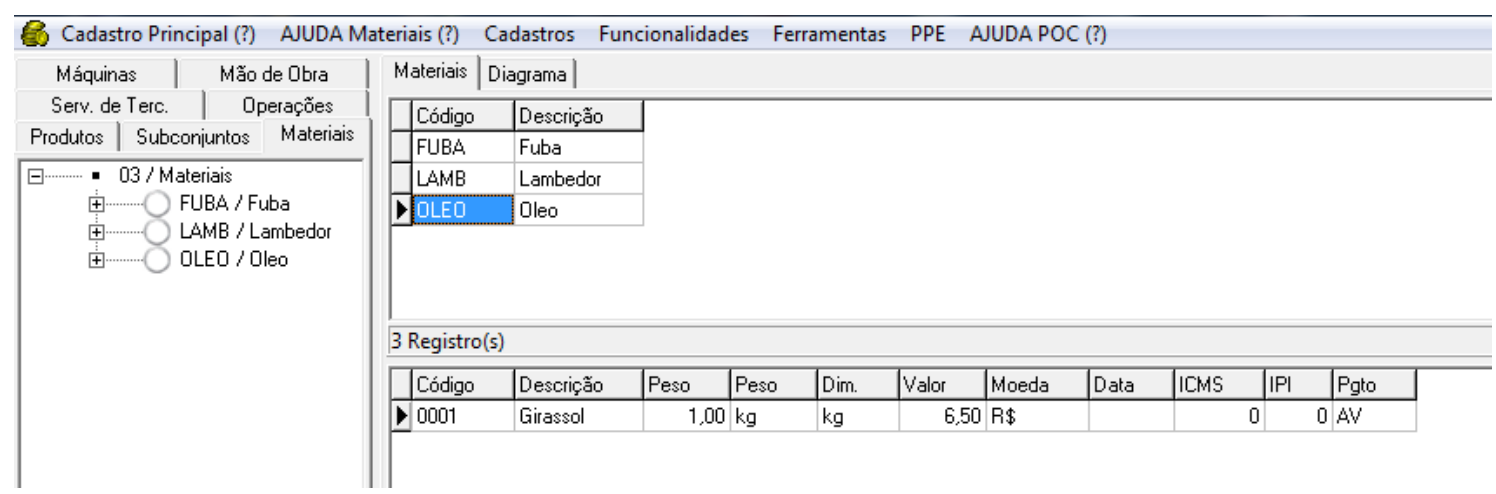

Figura 10: Cadastro do material utilizado na extração do óleo de giras sol.

Fonte: Autores, (2016).

$\mathrm{Na}$ sequência, foi realizado o cadastro da mão de obra direta, correspondente a dois trabalhadores, Figura 11, onde foi identificada a remuneração e a carga horária mensal dos trabalhadores. Vale salientar que foi considerado os encargos sociais e benefícios e que a carga de trabalho dos trabalhadores foi de 176 horas por mês. 


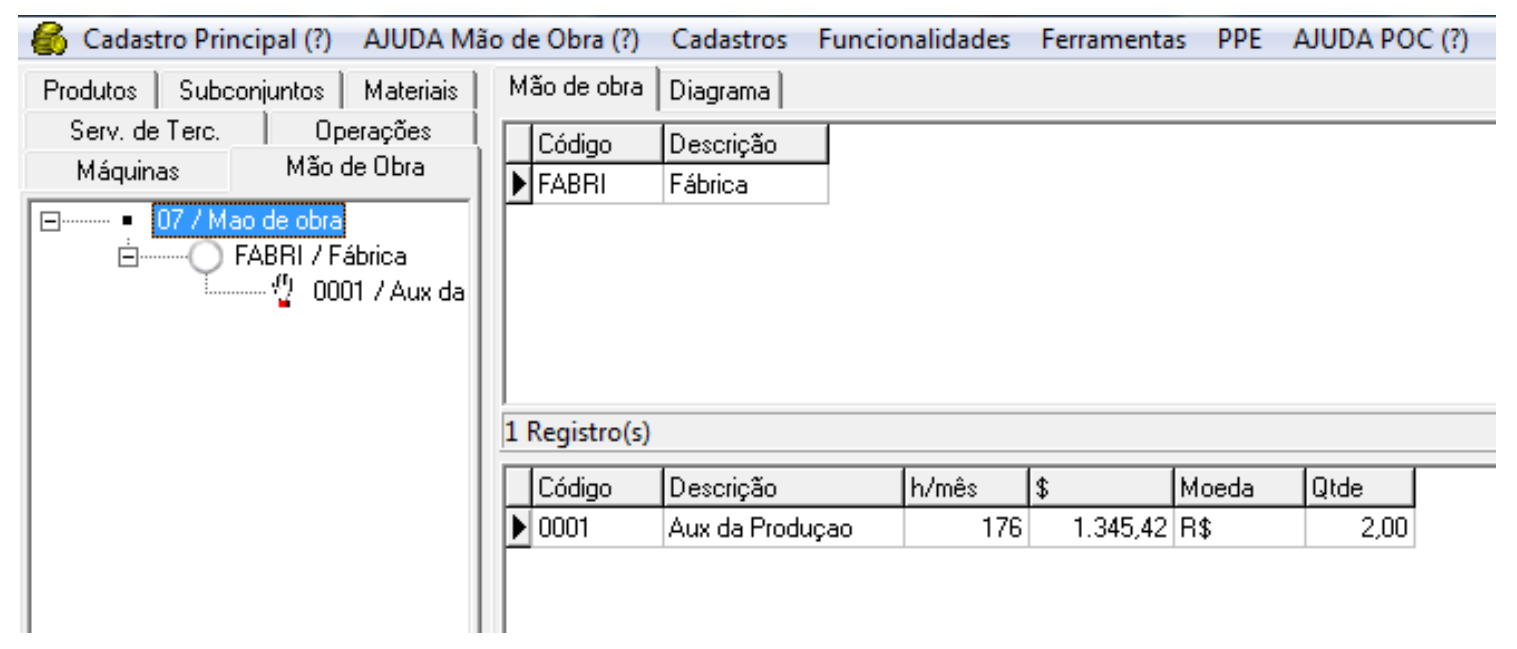

Figura 11: Cadastro da mão de obra direta no sistema.

Fonte: Autores, (2016).

Dando continuidade ao cadastro, foram adicionadas as informações referentes às operações existentes ao longo do processo produtivo. A Figura 12 apresenta todas as operações para a produção da fuba de milho e gergelim, lambedor e óleo de girassol.

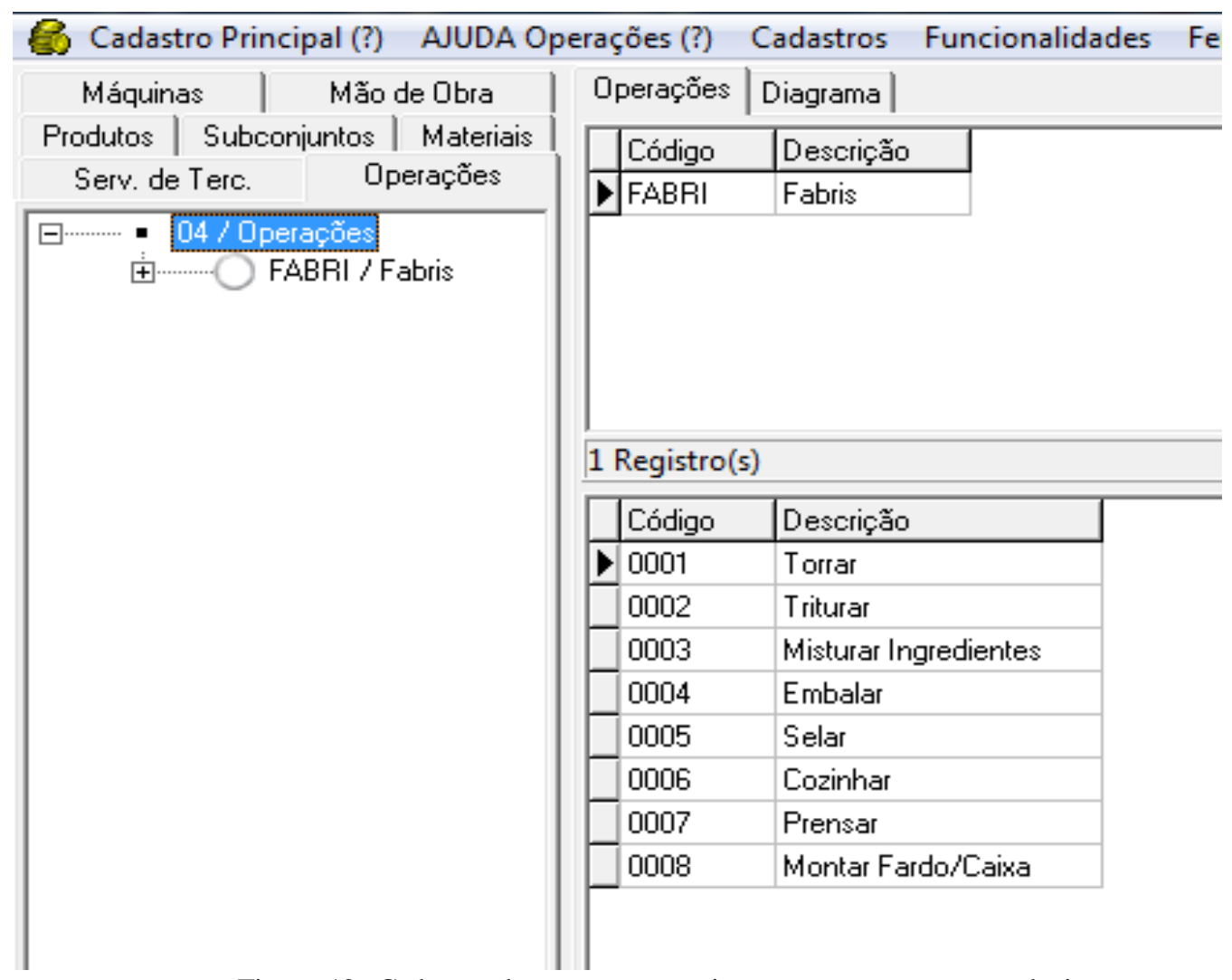

Figura 12: Cadastro das operações existentes no processo produtivo.

Fonte: Autores, (2016).

Finalizando essa primeira etapa com o cadastro de todas as máquinas utilizadas durante o processo produtivo dos produtos escolhidos para análise. Foram inseridos os valores de cada máquina, a vida útil, quantidade de horas utilizadas diariamente e a potencia de cada uma delas em watts, conforme mostra a Figura 13. Essas informações serviram de base para o cálculo do custo de energia elétrica resultante da utilização das máquinas durante o processo. 


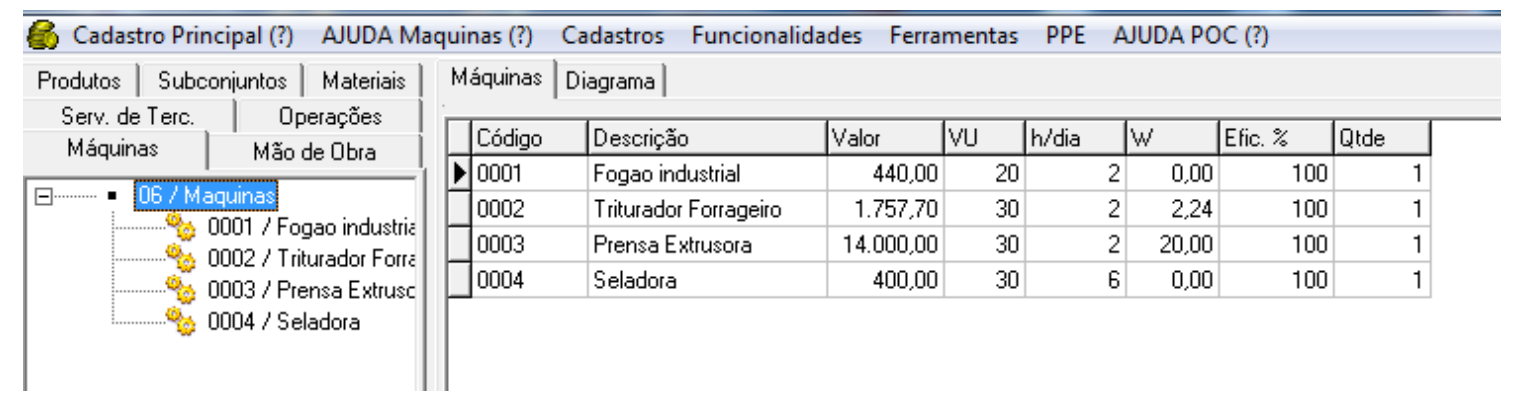

Figura 13: Cadastro das máquinas utilizadas no proces so.

Fonte: Autores, (2016).

Após o cadastro de todos os dados necessários na funcionalidade "cadastro primário", foi possível realizar a construção dos diagramas de fabricação de cada produto. As operações são fixadas no diagrama em ordem decrescente, ou seja, os primeiros processos são inseridos na parte superior. Todos os outros componentes produtivos são relacionados ao processo. Ainda no diagrama, é possível registrar as quantidades necessárias de cada um dos produtos selecionados. Sendo essas informações, fundamentais para o calculo dos custos unitários e das margens de contribuição dos produtos. Os diagramas de fabricação dos produtos podem ser visto nas Figuras 14, 15, 16 e 17, respectivamente:

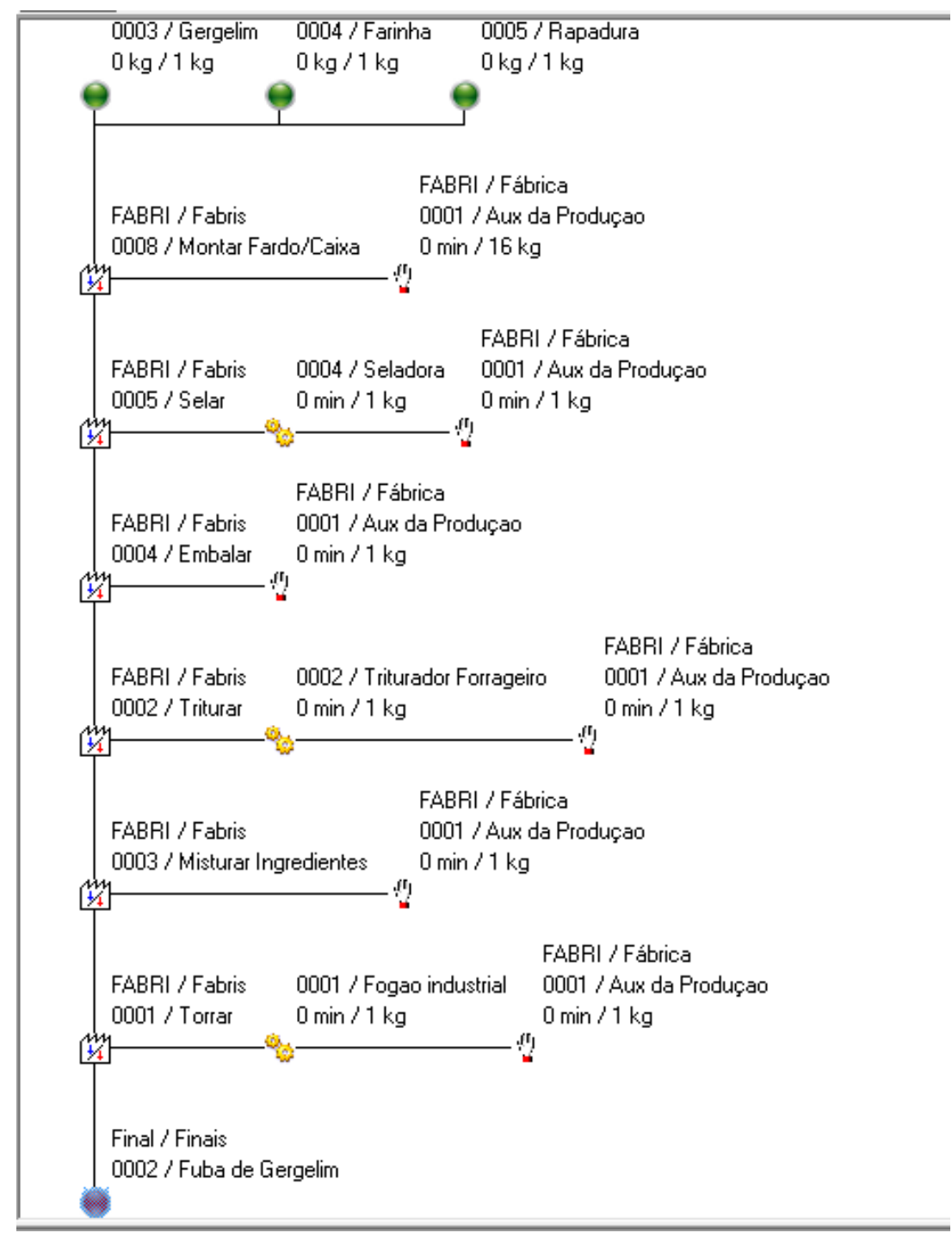

Figura 14: Cadastro das máquinas utilizadas no processo. Fonte: Autores, (2016). 
Praxedes et al., ITEGAM-JETIA. Vol. 03, № 10, pp.149-163. Junho, 2017.

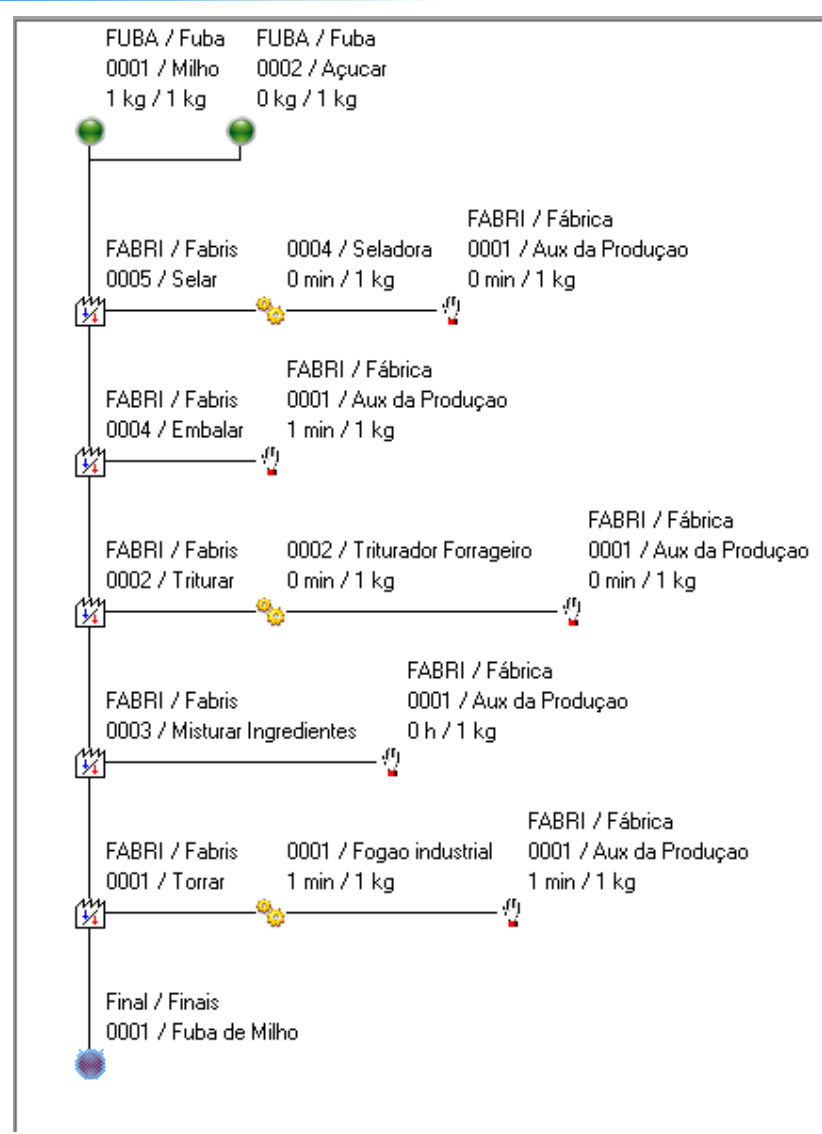

Figura 15: Diagrama de fabricação da fuba de milho. Fonte: Autores, (2016).

Figura 16: Diagrama de fabricação do lambedor.

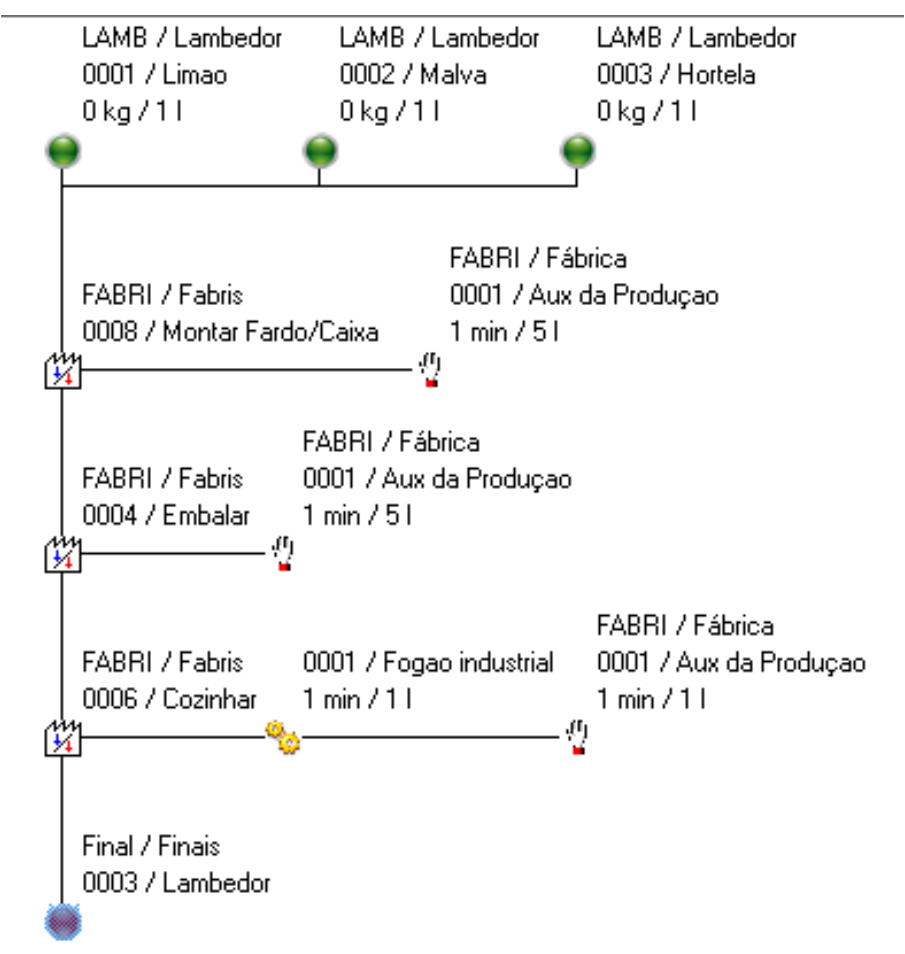

Figura 16: Diagrama de fabricação do lambedor.

Fonte: Autores, (2016). 


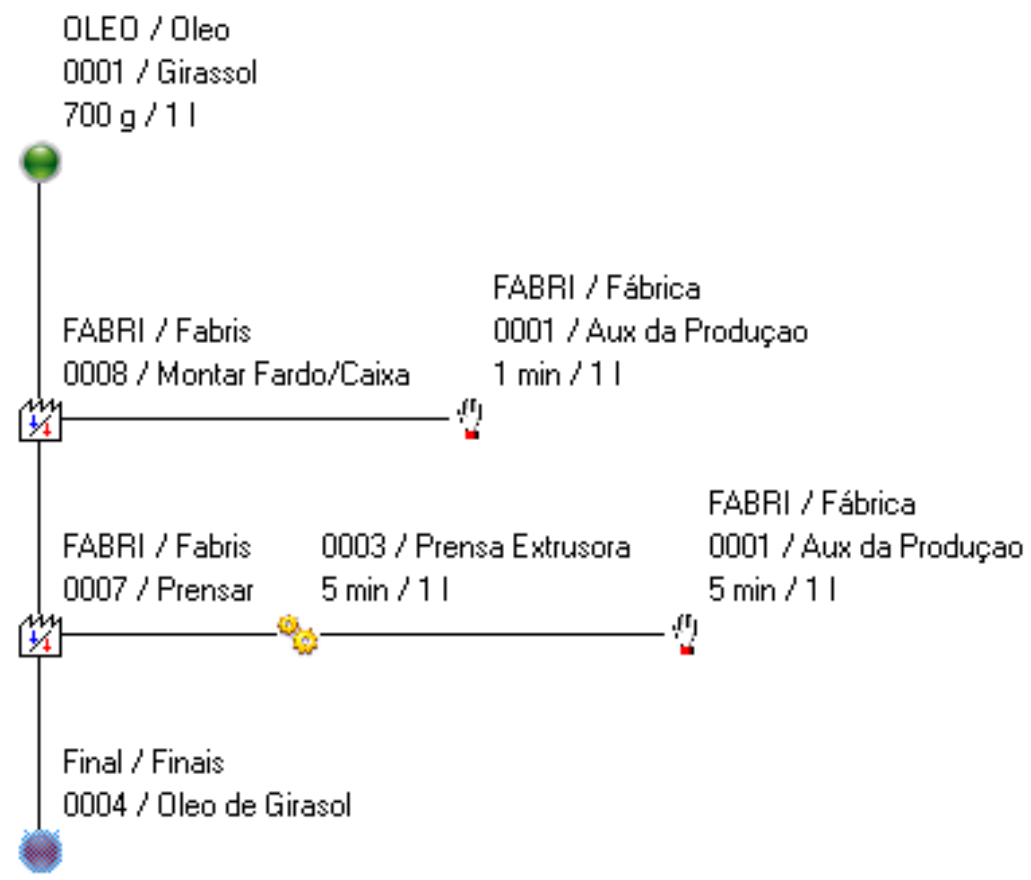

Figura 17:Diagrama de fabricação do óleo de girassol.

Fonte: Autores, (2016).

Assim, após o cadastro de todas as informações importantes ao processo e da construção do diagrama de fabricação, é possível visualizar o cálculo dos custos diretos de materiais, mão de obra e máquinas, despesas variáveis de venda e das margens de contribuições unitárias e totais para cada um dos produtos analisados no presente estudo, expondo em termos monetários e percentuais, conforme as Figuras 18, 19, 20 e 21, que apresenta os custos unitários e a margem de contribuição.

\begin{tabular}{|c|c|c|c|c|c|c|c|}
\hline \multicolumn{8}{|c|}{ Q Custo unitário } \\
\hline $\begin{array}{l}\text { 噼 } \\
\text { 皿 }\end{array}$ & \multicolumn{2}{|c|}{$\begin{array}{l}\text { Grupo: Final Finais } \\
\text { Código: } 0002 \\
\text { Descrição: Fuba de Gergelim }\end{array}$} & & & \multicolumn{3}{|c|}{$\begin{array}{l}\text { Estimativa: } 480,00 \mathrm{~kg} / \mathrm{mês} \\
\text { Preço: } \mathrm{R} \$ \quad 8,75 \quad / \mathrm{kg} \\
\text { Código do Processo: } 2\end{array}$} \\
\hline & Código & Descrição & Coef.Tec. & Unit. R\$ & Total R\$ & \% Parc. & \% Total \\
\hline 1 & & Faturamento & & 8,75 & 4.200 .00 & & 100,00 \\
\hline 1.1 & & Preço & & 8,75 & $4.200,00$ & 100,00 & 100,00 \\
\hline 1.2 & & Impostos por Fora & & 0,00 & 0,00 & 0,00 & 0,00 \\
\hline 2 & & Despesas Variáveis de Venda & & 1,58 & 756,00 & & 18,00 \\
\hline 2.1 & & Impostos por Dentro & & 1,58 & 756,00 & 100,00 & 18,00 \\
\hline & ICMS & ICMS & $18,00 \%$ & 1,58 & 756,00 & 100,00 & 0,00 \\
\hline 2.2 & & Impostos por Fora & & 0,00 & 0,00 & 0,00 & 0,00 \\
\hline 3 & & Custos Variáveis de Produção & & 4,12 & $1.978,00$ & & 47,10 \\
\hline 3.1 & & Custo de Materiais & & 3.76 & $1.804,80$ & 91,24 & 42,97 \\
\hline & 0004 & Farinha & $0,40 \mathrm{~kg}$ & 1,48 & 710,40 & 39,36 & 16,91 \\
\hline & 0003 & Gergelim & $0,40 \mathrm{~kg}$ & 1,40 & 672,00 & 37,23 & 16,00 \\
\hline & 0005 & Rapadura & $0,20 \mathrm{~kg}$ & 0,88 & 422,40 & 23,40 & 10,06 \\
\hline 3.2 & & Custos de Serviço de Terceiros & & 0,00 & 0,00 & 0,00 & 0,00 \\
\hline 3.3 & & Custos de Mão-de-Obra & & 0,35 & 169,59 & 8.57 & 4,04 \\
\hline & 0001 & Aux da Produçao & $0,03 \mathrm{~h}$ & 0,35 & 169,59 & 100,00 & 4,04 \\
\hline 3.4 & & Custos de Máquinas & & 0,01 & 3,61 & 0,18 & 0,09 \\
\hline & 0002 & Triturador Forrageiro & $0,01 \mathrm{~h}$ & 0,01 & 2.44 & 67.65 & 0,06 \\
\hline & 0001 & Fogao industrial & $0,01 \mathrm{~h}$ & 0,00 & 0,61 & 16,96 & 0,01 \\
\hline & 0004 & Seladora & $0,01 \mathrm{~h}$ & 0,00 & 0,56 & 15,39 & 0,01 \\
\hline 4 & & Margem Real & & 3,05 & $1.466,00$ & & 34,90 \\
\hline
\end{tabular}

Figura 18: Custos unitários e margem de contribuição da fuba de gergelim. Fonte: Autores, (2016). 
Praxedes et al., ITEGAM-JETIA. Vol. 03, Nº 10, pp.149-163. Junho, 2017.

\begin{tabular}{|c|c|c|c|c|c|c|c|}
\hline \multicolumn{8}{|c|}{ B Custo unitário } \\
\hline $\begin{array}{l}\text { 吗 } \\
\text { 且 }\end{array}$ & \multicolumn{2}{|c|}{$\begin{array}{l}\text { Grupo: Final Finais } \\
\text { Código: } 0001 \\
\text { Descrição: Fuba de Milho }\end{array}$} & & & \multicolumn{3}{|c|}{$\begin{array}{l}\text { Estimativa: } 480,00 \mathrm{~kg} / \mathrm{mês} \\
\text { Preço: } \mathrm{R} \$ \quad 8,75 \quad / \mathrm{kg} \\
\text { Código do Processo: } 1\end{array}$} \\
\hline & Código & Descrição & Coef.Tec. & Unit. R\$ & Total R\$ & \% Parc. & $\%$ Total \\
\hline 1 & & Faturamento & & 8,75 & $4.200,00$ & & 100,00 \\
\hline 1.1 & & Preço & & 8.75 & $4.200,00$ & 100,00 & 100,00 \\
\hline 1.2 & & Impostos por Fora & & 0,00 & 0,00 & 0,00 & 0,00 \\
\hline 2 & & Despesas Variáveis de Venda & & 1,58 & 756,00 & & 18,00 \\
\hline 2.1 & & Impostos por Dentro & & 1,58 & 756,00 & 100,00 & 18,00 \\
\hline & ICMS & ICMS & $18,00 \%$ & 1,58 & 756,00 & 100,00 & 0,00 \\
\hline 2.2 & & Impostos por Fora & & 0,00 & 0,00 & 0,00 & 0,00 \\
\hline 3 & & Custos Variáveis de Produção & & 5,83 & $2.797,80$ & & 66,61 \\
\hline 3.1 & & Custo de Materiais & & 0,81 & 390,00 & 13,94 & 9,29 \\
\hline & 0001 & Milho & $0,75 \mathrm{~kg}$ & 0,45 & 216,00 & 55,38 & 5,14 \\
\hline & 0002 & Açucar & $0,25 \mathrm{~kg}$ & 0,36 & 174,00 & 44,62 & 4,14 \\
\hline 3.2 & & Custos de Serviço de Terceiros & & 0,00 & 0,00 & 0,00 & 0,00 \\
\hline 3.3 & & Custos de Mão-de-0bra & & 5,01 & $2.403,96$ & 85,92 & 57,24 \\
\hline & 0001 & Aux da Produçao & $0,38 \mathrm{~h}$ & 5,01 & $2.403,96$ & 100,00 & 57,24 \\
\hline 3.4 & & Custos de Máquinas & & 0,01 & 3,84 & 0,14 & 0,09 \\
\hline & 0002 & Triturador Forrageiro & $0,01 \mathrm{~h}$ & 0,01 & 2,44 & 63,65 & 0,06 \\
\hline & 0001 & Fogao industrial & $0,01 \mathrm{~h}$ & 0,00 & 0,84 & 21,86 & 0,02 \\
\hline & 0004 & Seladora & $0,01 \mathrm{~h}$ & 0,00 & 0,56 & 14,49 & 0,01 \\
\hline 4 & & Margem Real & & 1,35 & 646,20 & & 15,39 \\
\hline
\end{tabular}

Figura 19: Custos unitários e margem de contribuição da fuba de milho. Fonte: Autores, (2016).

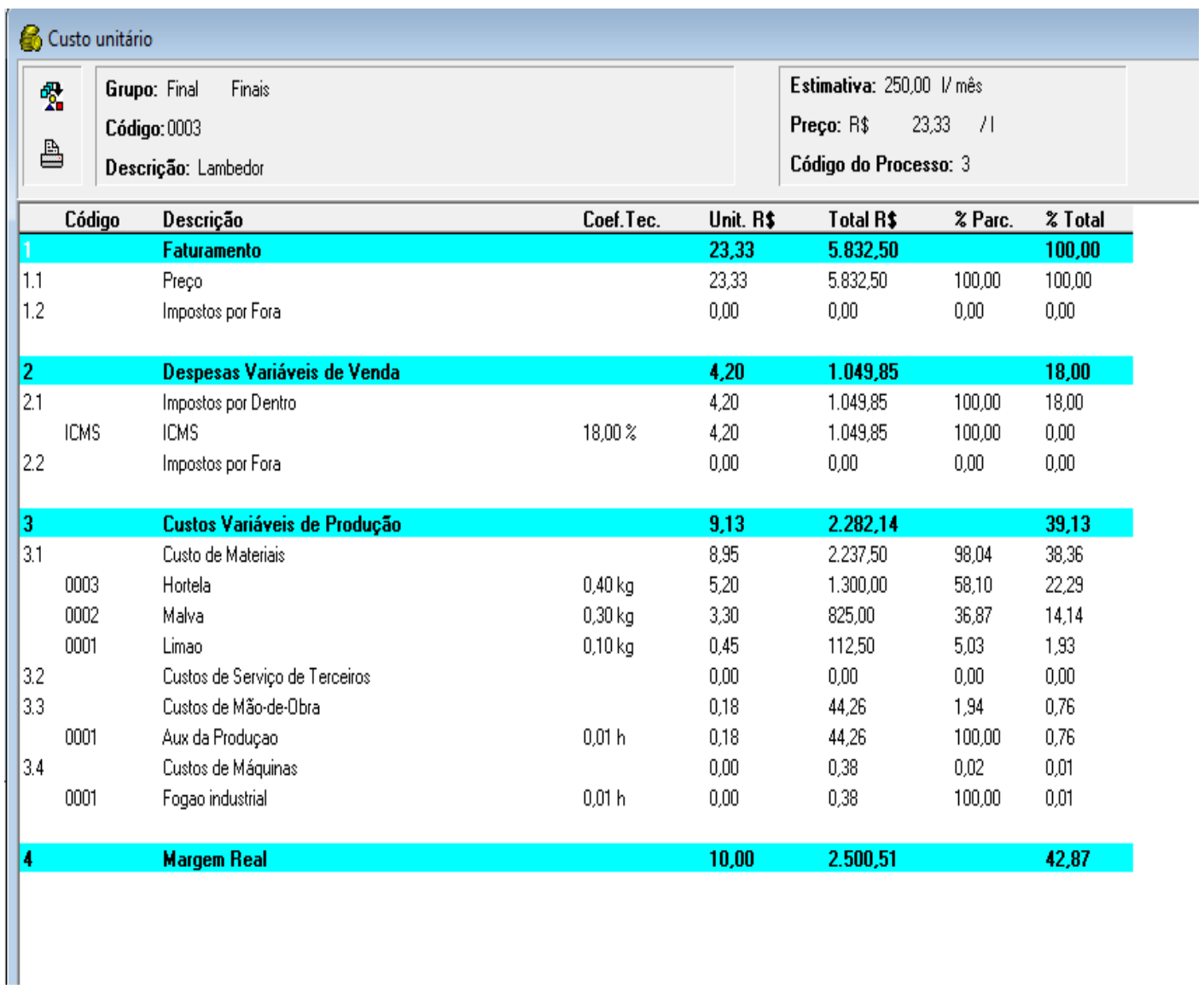

Figura 20: Custo unitário e margem de contribuição do lambedor.

Fonte: Autores, (2016). 
Praxedes et al., ITEGAM-JETIA. Vol. 03, № 10, pp.149-163. Junho, 2017.

\begin{tabular}{|c|c|c|c|c|c|c|c|}
\hline \multicolumn{8}{|c|}{ Q Custo unitário } \\
\hline \multirow[t]{2}{*}{ 影 } & \multicolumn{2}{|c|}{$\begin{array}{l}\text { Grupo: Final Finais } \\
\text { Código:0004 } \\
\text { Descrição: Oleo de Girasol }\end{array}$} & & & \multicolumn{3}{|c|}{$\begin{array}{l}\text { Estimativa: } 60,00 \mathrm{l} / \mathrm{mês} \\
\text { Preço: } \mathrm{R} \$ \quad 73,33 \quad / / \\
\text { Código do Processo: } 4\end{array}$} \\
\hline & Código & Descrição & Coef.Tec. & Unit. R\$ & Total R\$ & \% Parc. & $\%$ Total \\
\hline 1 & & Faturamento & & 73,33 & $4.399,80$ & & 100,00 \\
\hline 1.1 & & Preço & & 73,33 & $4.399,80$ & 100,00 & 100,00 \\
\hline 1.2 & & Impostos por Fora & & 0,00 & 0,00 & 0,00 & 0,00 \\
\hline 2 & & Despesas Variáveis de Venda & & 13,20 & 791,96 & & 18,00 \\
\hline 2.1 & & Impostos por Dentro & & 13,20 & 791,96 & 100,00 & 18,00 \\
\hline & ICMS & ICMS & $18,00 \%$ & 13,20 & 791,96 & 100,00 & 0,00 \\
\hline 2.2 & & Impostos por Fora & & 0,00 & 0,00 & 0,00 & 0,00 \\
\hline 3 & & Custos Variáveis de Produção & & 6,42 & 384,91 & & 8,75 \\
\hline 3.1 & & Custo de Materiais & & 4,55 & 273,00 & 70,92 & 6,20 \\
\hline & 0001 & Girassol & $0,70 \mathrm{~kg}$ & 4,55 & 273,00 & 100,00 & 6,20 \\
\hline 3.2 & & Custos de Serviço de Terceiros & & 0,00 & 0,00 & 0,00 & 0,00 \\
\hline 3.3 & & Custos de Mão-de-0bra & & 1,22 & 73,03 & 18,97 & 1,66 \\
\hline & 0001 & Aux da Produçao & $0,09 \mathrm{~h}$ & 1,22 & 73,03 & 100,00 & 1,66 \\
\hline 3.4 & & Custos de Máquinas & & 0,65 & 38,89 & 10,10 & 0,88 \\
\hline & 0003 & Prensa Extrusora & $0,08 \mathrm{~h}$ & 0,65 & 38,89 & 100,00 & 0,88 \\
\hline 4 & & Margem Real & & 53,72 & $3.222,92$ & & 73,25 \\
\hline
\end{tabular}

Figura 21: Custo unitário e margem de contribuição do óleo de giras sol.

Fonte: Autores, (2016).

Podemos observar nas Figuras 17, 18, 19 e 20 que o óleo de girassol é a que possui a maior margem real de contribuição, com $73,25 \%$, já o produto com a menor margem foi a fuba de milho, com 15,39\%. Margem de contribuição é a quantia monetária que sobra da receita obtida através da venda do produto após a retirada dos gastos variáveis, que representa as despesas e os custos variáveis. Vale destacar que a funcionalidade

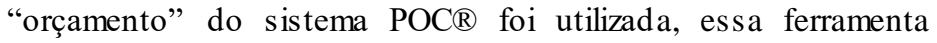
permite relacionar o preço de venda com uma estimativa de margem de contribuição mínima de $10 \%$ e maxima de $30 \%$, simulando o preço de venda e mostrando em planilhas os custos e as despesas relacionadas, com tudo, são dis ponibilizados gráficos de sensibilidade relacionando preços e margens de contribuição.

Com outra funcionalidade do sistema POC®, foi possível verificar o custo total mensal de cada tipo de material utilizado na fabricação dos produtos analisados na empresa, conforme mostra a Figura 22:

\begin{tabular}{|c|c|c|c|c|}
\hline \multicolumn{5}{|c|}{ 8. Cadastros Funcionalidades Ferramentas PPE AUUDA POC (?) } \\
\hline \multicolumn{5}{|c|}{ Grupo: } \\
\hline Código: & Descrição: Planejamento para Modelo. & & & \\
\hline CRP. Máquinas & | CRP·Mẫode-Obra | MRP·Subconiuntos: MRP·Materialis & Serviços de Terceiros & & \\
\hline Grupo Código & Descrição & \begin{tabular}{|l|l} 
Utilizado & Dimen. \\
\end{tabular} & Custo Unit. & Custo Total \\
\hline FISBA 0001 & Milho & $360,00 \mathrm{~kg}$ & 0,60 & 216,00 \\
\hline FUBA 0002 & Açucar & $120,00 \mathrm{~kg}$ & 1,45 & 174,00 \\
\hline FIBBA 0003 & Gergelim & $192,00 \mathrm{~kg}$ & 3,50 & 672,00 \\
\hline FUBA 0004 & Fairinha & $192,00 \mathrm{~kg}$ & 3,70 & 710,40 \\
\hline FIUBA 0005 & Rapadura & $96,00 \mathrm{~kg}$ & 4,40 & 422,40 \\
\hline LAMB 0001 & Limao & $25,00 \mathrm{~kg}$ & 4,50 & 112,50 \\
\hline LAMB 0002 & Malva & $75,00 \mathrm{~kg}$ & 11,00 & 825,00 \\
\hline LAMB 0003 & Hottela & $100,00 \mathrm{~kg}$ & 13,00 & $1.300,00$ \\
\hline JOLEO 0001 & Girassol & $42,00 \mathrm{~kg}$ & 6,50 & 273,00 \\
\hline
\end{tabular}

Figura 22: MRP I dos materiais.

Fonte: Autores, (2016). 
Com base nas informações apresentadas acima, o sistema materiais da empresa analis ada, de acordo com a Figura 22:

POC® possibilitou a construção da curva $\mathrm{ABC}$ de custos de

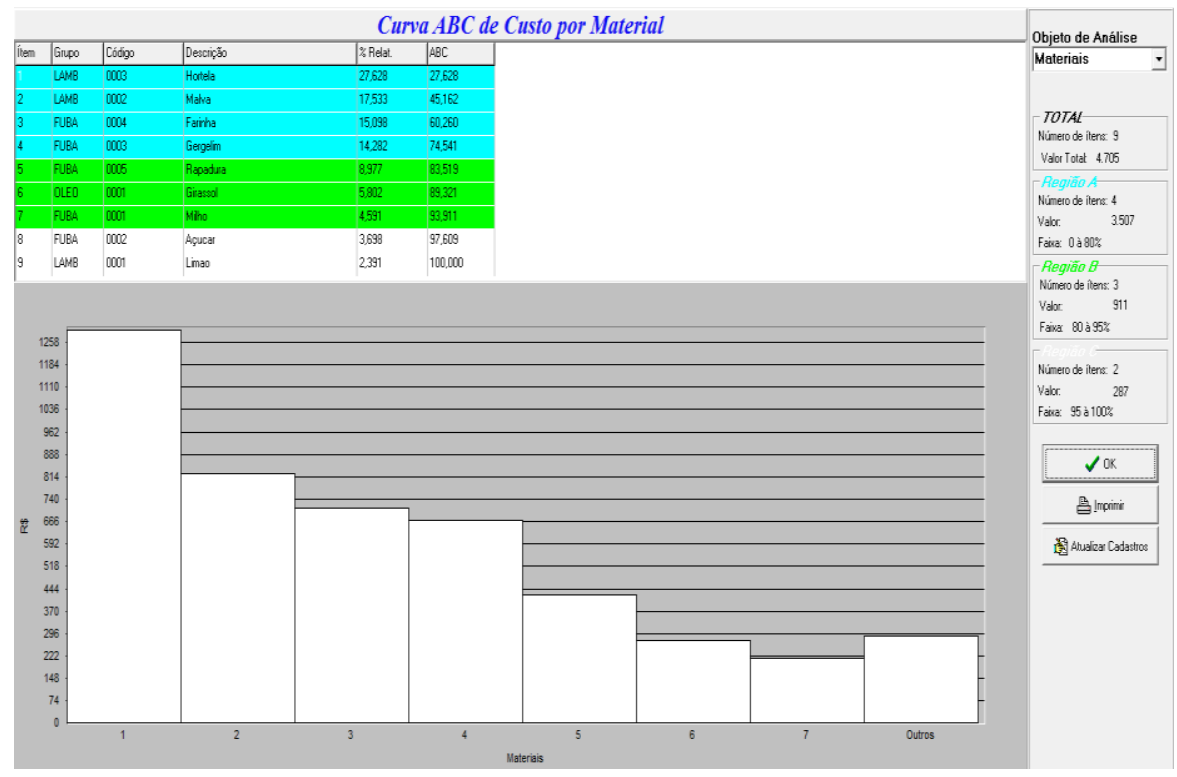

Figura 23: Curva ABC de custos de materiais.

Fonte: Autores, (2016).

A curva $\mathrm{ABC}$ de custos de materiais possibilitou identificar que a Hortelã representou 27,628 do custo total com materiais do período. Já os materiais malva, farinha, gergelim, rapadura, girassol, milho, açúcar e limão, representaram respectivamente $17,533 \% ; 15,099 \% ; 14,282 \% ; 8,977 \% ; 5,802 \%$; $4,591 \% ; 3,698 \% ; 2,391 \%$.

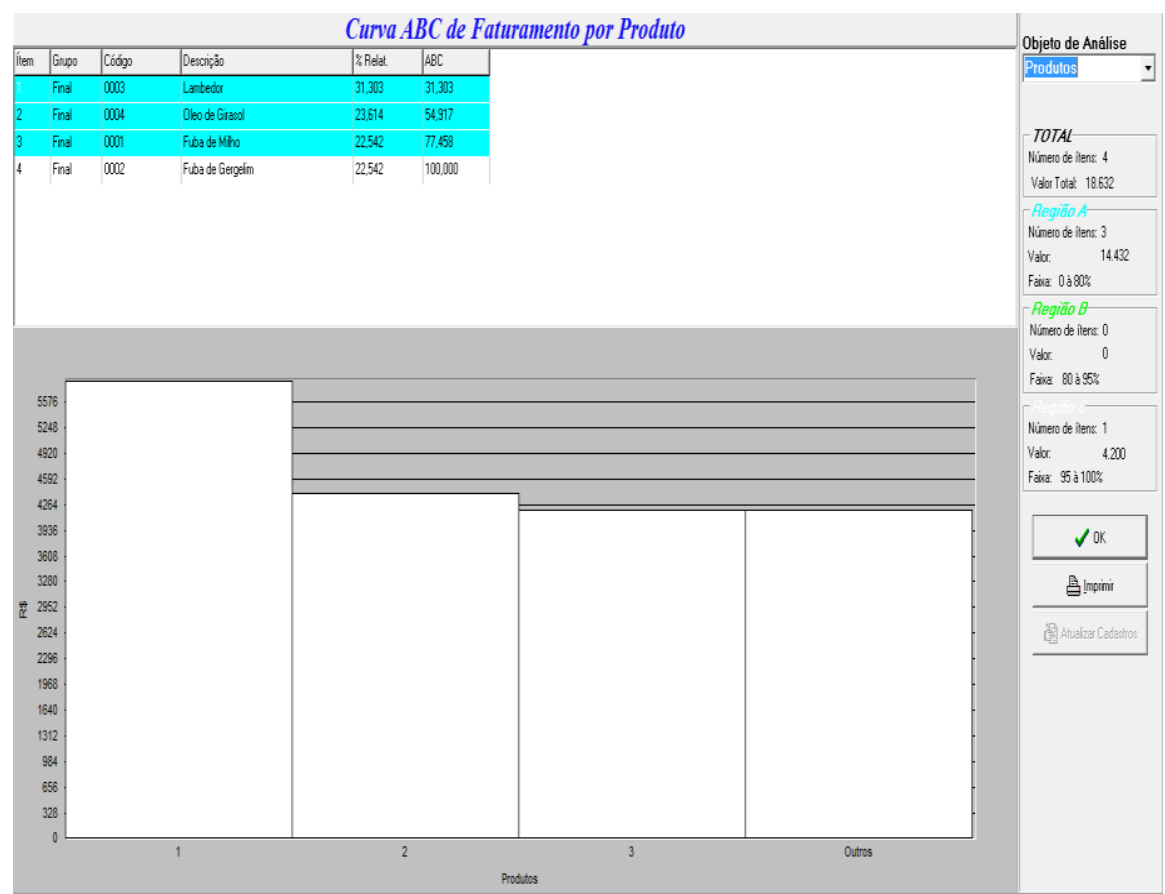

Figura 24: Curva ABC do faturamento de produtos. Fonte: Autores, (2016).
Conforme as informações relativas aos preços de venda e às quantidades mensalmente vendidas, foi possível a construção da curva $\mathrm{ABC}$ de faturamento dos produtos analisados da empresa, da forma que mostra a Figura 24: 
girassol representa 23,634\%; a fuba de milho e de gergelim representa cada uma $22,542 \%$. Esses números possibilitaram aos gestores da empresa identificar quais os produtos possuem uma maior representatividade nos lucros da empresa, como também, quais produtos possuem as menores participações no faturamento mensal da empresa.

Cadastros Funcionalidades Ferramentas PPE AUUDAPOC(?)

Grupo:

Código:

Descriçăa: Planejamento para Modelo.

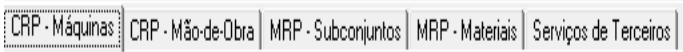

\begin{tabular}{|c|c|c|c|c|c|c|c|c|c|c|c|c|c|}
\hline Código & Descriç̧̃o & Qidde P. & Valor $R \$$ & V. Útil(anos) & Eficiência $\%$ |h & h/dia & PotênciakW/h & hPoss. / mês & Qidde Litil/mês/h & tilmês & Aprov. \% F & $\$ \$ / h / R$ & $\$ / \mathrm{mês}$ \\
\hline 0001 & Fogao industrial & 1,00 & (]) 440,00 & 20,00 & 100,00 & 2,00 & 0,00 & 40,00 & 0,25 & 9,97 & 24,93 & 0,18 & 1,83 \\
\hline 0002 & Triturador Forrageiro & 1,00 & $1.757,70$ & 30,00 & 100,00 & 2,00 & 2,24 & 40,00 & 0,17 & 6,66 & 16,64 & 0,73 & 4,80 \\
\hline 0003 & Prensa Extrusora & 1,00 & $14,000,00$ & 30,00 & 100,00 & 2,00 & 20,00 & 40,00 & 0,13 & 5,00 & 1250 & 7,78 & 38,89 \\
\hline 00004 & Seladora & 1,00 & 400,00 & 30,00 & 100,00 & 6,00 & 0,00 & 120,00 & 0,06 & 6,66 & 5,55 & 0,17 & 1,11 \\
\hline
\end{tabular}

Figura 25: CRP das máquinas.

Fonte: Autores, (2016).

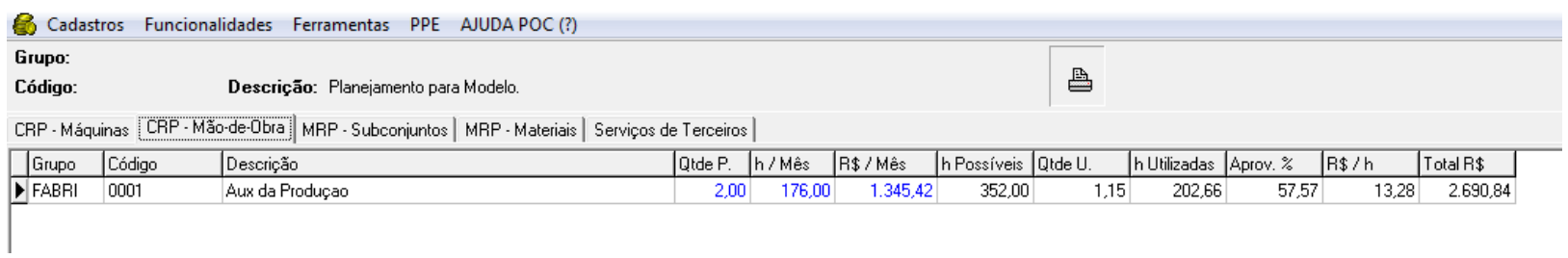

Figura 26: CRP da mão de obra.

Fonte: Autores, (2016).

Por fim, o sistema POC® na funcionalidade "resultados" gerou um gráfico com as curvas de faturamento, de custos e despesas fixas, custo e despesas variáveis e custos e despesas totais do período em analise, possibilitando a visualização do ponto de equilíbrio contábil da empres a em termos de faturamento conforme mostra a Figura 27:

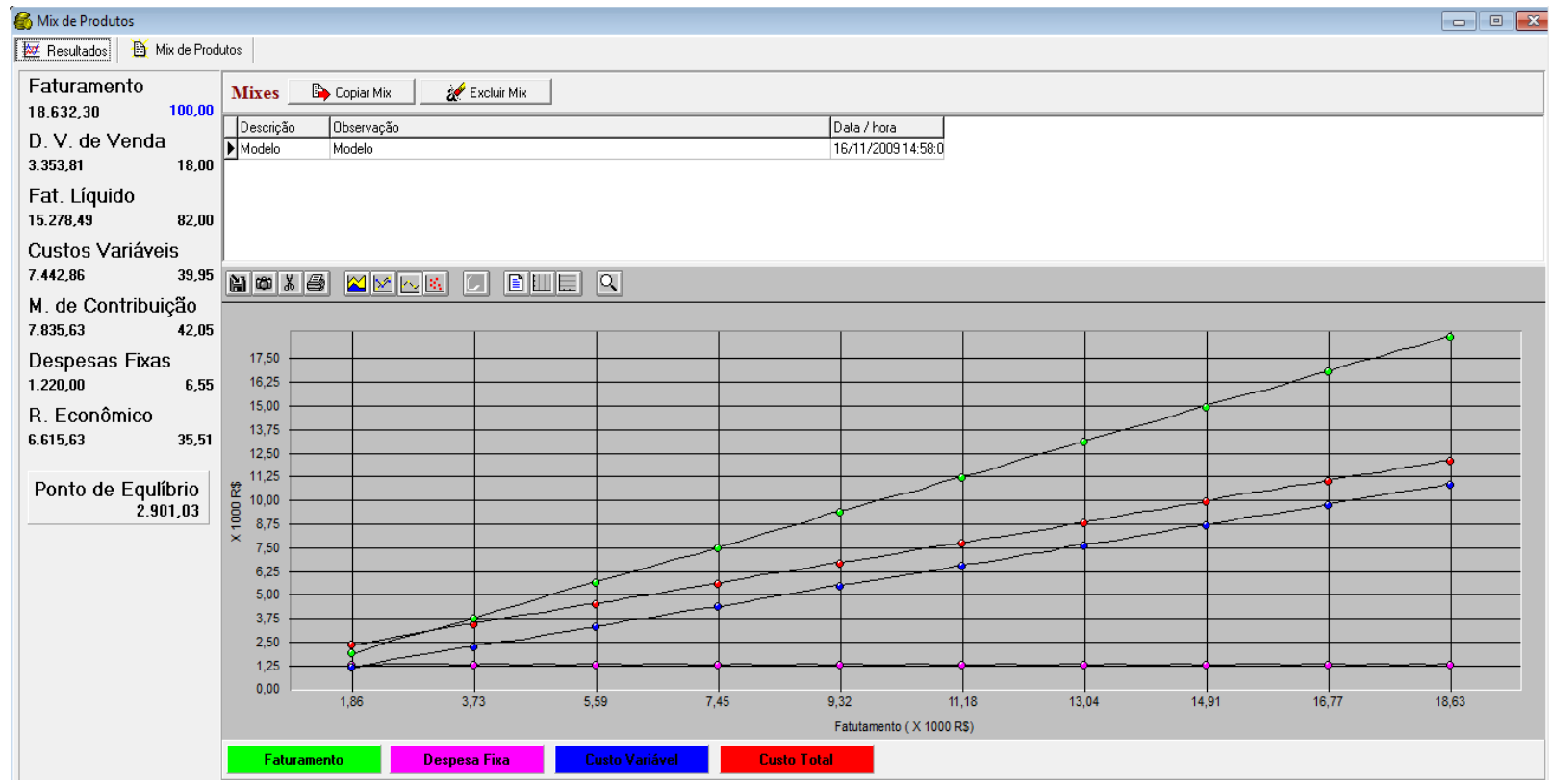

Figura 27: Ponto de equilíbrio da empresa.

Fonte: Autores, (2016). 
Baseando-se na figura acima apresentada, pode-se notar que para empresa ter lucro, faz-se necessário um faturamento bruto de $\mathrm{R} \$ 2.901,03$. Com tudo, o faturamento mensal da empresa ( $\mathrm{R} \$ 18.632,30)$, projetado para o mix de produtos analisados no presente estudo, foi bem maior ao faturamento necessário para que a empresa atingisse o ponto de equilíbrio contábil. O lucro mensal foi de $\mathrm{R} \$ 6.615,63$ e uma lucratividade de $35,51 \%$ no período analisado.

\section{CONCLUSÃO}

O trabalho foi de fundamental importância para que pudéssemos dimensionar a relevância das ferramentas de custos no auxílio à tomada de decisões e consequentemente, seu grande poder na gestão e competitividade de uma empresa. Dentre as dificuldades, o fato de ser a primeira vez que utilizamos o software POC®, foi um fator que exigiu grande desprendimento, visto que tivemos que recorrer inúmeras vezes ao auxílio de bibliografias e a orientadora deste artigo. Porém, tal situação possibilitou o entendimento desta feramente auxiliar tão importante. Como sugestão, é fundamental que em trabalhos futuros se busque antes da aplicação do método, uma considerável padronização dos elementos de produção, facilitando assim a coleta de dados e possibilitando resultados mais realistas. Essa estandardização também facilitaria mudanças decorrentes da tomada de decisões. Na empresa estudada, apesar da mesma está apresentando lucros consecutivos e com uma boa margem real, ela não apresenta uma eficaz mensuração de seus custos, visto que seu método está calçado apenas em mensurações e equações básica, o que dificulta aos gestores visualizarem a real situação do empreendimento. Sendo assim, é conveniente que este trabalho, assim como a ferramenta utilizada, possa ser utilizado continuamente pela empresa em todo o seu portfólio, de maneira irrestrita. Para trabalhos futuros, sugere-se primeiramente a padronização dos processos produtivos e o estudo através do sistema POC@ com todos os produtos da empresa.

\section{REFERÊNCIAS}

[1] Atkinson, A. A.; Banker, R. D.; Kaplan, R. S.; Young, S. M.

Contabilidade gerencial. São Paulo: Atlas, 2000.

[2] Garrison, R. W., Von Ellenrieder, N., and Louton, J. A. 2006. Dragonfly Genera of the New World. Johns Hopkins University Press, Baltimore.

[3] Martins, Fran. "Contratos e obrigações comerciais." (2010).

[4] Costa, Reinaldo Pacheco da; FERREIRA, Hellis on Akira Shimada; SARAIVA JR., Abraão Freires. Preços, Orçamentos e custos industriais: Fundamentos da gestão de custos e de preços industriais. Rio de Janeiro: Elsevier, 2010.

[5] Horngren, Charles T. "Choosing accounting practices for reporting to management." NAA Bulletin 44.1 (1962): 5.

[6] Leone, George SG. "Contabilidade de custos." São Paulo: Atlas (2000).

[7] Bornia, A. C. Análise gerencial de custos: aplicação em empresas modernas. São Paulo: Bookman, 2002.
[8] SEBRAE. Gestão Financeira: Ponto de equilíbrio. Disponível em $<$ http://www.sebrae.com.br/sites/PortalSebrae/artigos/ponto-deequilibrio>. Acesso em: 22/11/2016.

[9] Slack, Nigel; Chanbers, Stuart; Johnston Robert Johnston. Administração da produção. 2. ed. São Paulo: Atlas, 2002.

[10] Araújo, Marco Antônio de. Administração de produção e operações. 2. ed. Rio de Janeiro: Brasport, 2009.

[11] Pinto, C. V. Organização e Gestão da Manutenção. 2. ed. Lisboa: Edições Monitor, 2002.

[12] Bruni, A. L.; Famá, R. Eficiência, previsibilidade dos preços e anomalias em mercados de capitais: teoria e evidências. Caderno de Pesquisas em Administração, São Paulo: PPGA/FEA/USP, v. 1, n. 7, p. 71-85, 2º trim. 1998.

[13] Dias, M. A. P. Administração de Materiais: resumo da teoria, questões de revisão, exercícios, estudos de casos. 4. ed. São Paulo: Atlas, 1995.

[14] Gil Antonio Carlos. Como elaborar projetos de pesquisa. 4. ed. São Paulo: Atlas, 2002.

[15] Lakatos, E.M.; Marconi, M.A. Fundamentos de metodologia científica. 7. ed. São Paulo: Atlas, 2010.

[16] Godoi, Christiane Kleinübing; Bandeira-de-Mello, Rodrigo; Da Silva, Anielson Barbosa - Pesquisa Qualitativa em Estudos Organizacionais: Paradigmas, Estratégias e Métodos. $2^{\mathrm{a}}$ Edição. Ed. Saraiva. São Paulo, 2010. 